\section{Large bleeding rectal varices treated with endo- scopic ultrasound-guided coiling and cyanoacrylate injection}
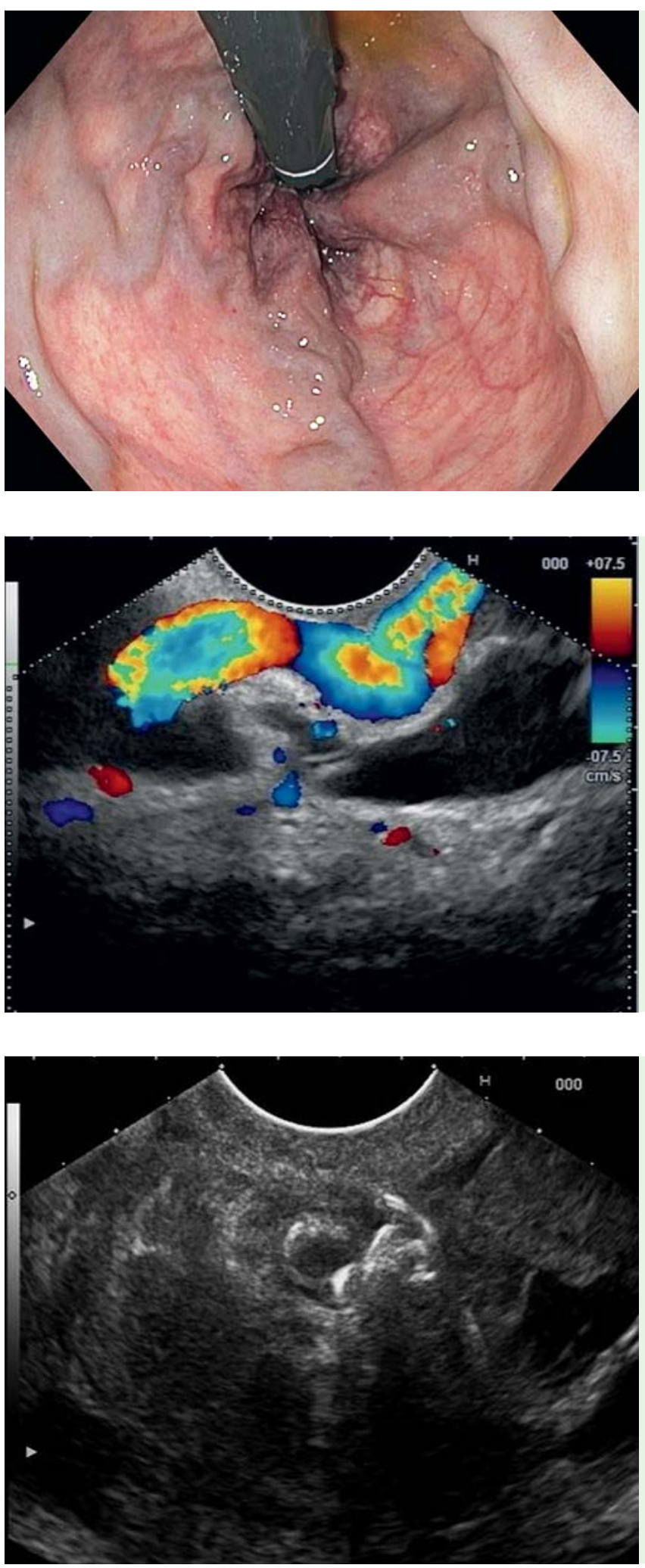

Fig. 1 Endoscopic view of the three variceal columns $(3,6$, and $5 \mathrm{~cm}$ proximal to the dentate line.

Fig. 2 Color Doppler sonographic view of the treated variceal column revealing active blood flow prior to endoscopic ultrasoundguided angiotherapy.

Fig. 3 Endoscopic ultrasound image demonstrating the embolization coil 9 o'clock), extending within the varix.
There is no consensus as to the optimal treatment strategy for bleeding rectal varices. Current endoscopic options include endoscopic injection sclerotherapy and band ligation. We present the successful use of endoscopic ultrasound (EUS)-guided coil placement and cyanoacrylate injection in obliterating symptomatic large rectal varices.

A 78-year-old woman with cryptogenic cirrhosis presented after multiple admissions for large-volume hematochezia. Esophagogastroduodenoscopy revealed grade 2 gastroesophageal varices. Colonoscopy revealed three distinct variceal columns extending $5 \mathrm{~cm}$ proximally from the dentate line ( $\bullet$ Fig. 1 ). Lower EUS with color Doppler revealed a large feeding varix measuring $45 \times 12 \mathrm{~mm}$ ( Fig.2) Under sonographic guidance, a 19-gauge needle preloaded with a $10 \mathrm{~mm}$ embolization coil (MReye, Cook Medical, Winston Salem, NC, USA) was used to puncture the feeding varix and intravariceal coil deployment was confirmed sonographically (๑ Fig.3). This was immediately followed by injection of $1 \mathrm{ml}$ of $\mathrm{N}$-butyl 2-cyanoacrylate (Histoacryl; B. Braun Medical, Bethlehem, PA, USA) and $1.5 \mathrm{ml}$ of $5 \%$ dextrose. Subsequent color Doppler demonstrated significantly attenuated flow.

EUS with color Doppler 2 weeks later revealed ongoing flow within the previously treated varix, now measuring $15 \times 9 \mathrm{~mm}$. The procedure was repeated as described above, though on this occasion $2 \mathrm{ml}$ of cyanoacrylate was injected following coil deployment to ensure complete obliteration. Cessation of blood flow was confirmed via Doppler US. At 4-week followup the patient complained of anal pruritus but no hematochezia. Sigmoidoscopy revealed thrombosed varices, two areas of ulceration, and extravasation of cyanoacrylate encroaching onto the dentate line ( Fig.4). The anal pruritus was successfully managed with topical 3\% lidocaine/2.5\% hydrocortisone ointment. No rectal bleeding was reported at 12 -week follow-up.

Large $(>3 \mathrm{~cm})$ rectal varices are challenging to treat with cyanoacrylate alone, because of the excessive volume of cyanoacrylate needed, which increases the risk of systemic embolization [1,2]. Embolization coils occupy part of the variceal volume and offer a scaffold for cyanoacrylate which permits the use of smaller volumes of cyanoacrylate, thereby decreasing the risk of systemic embolization [3]. Cyanoacrylate extravasation is less tolerated in 


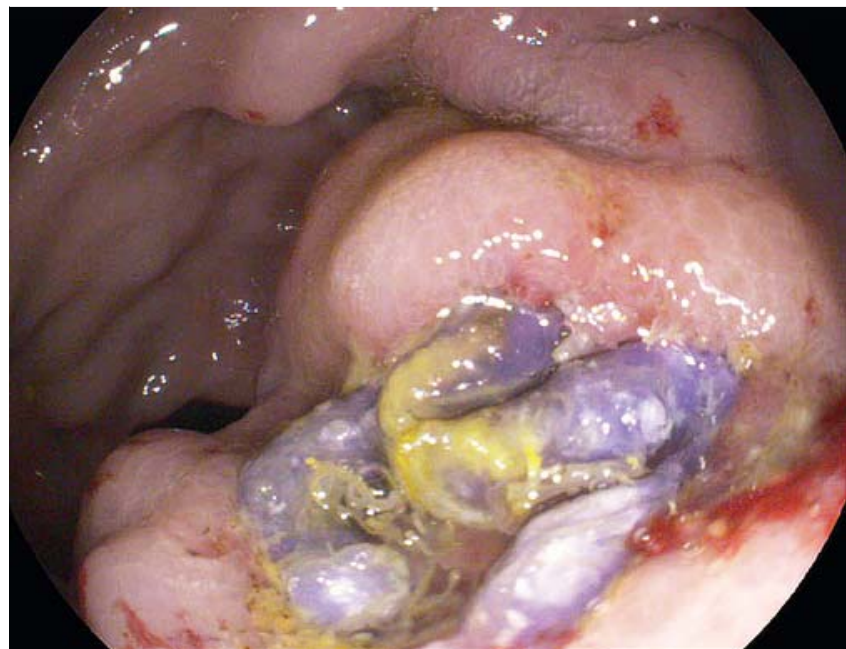

Fig. 4 Sigmoidoscopy at 4-week follow-up showing cyanoacrylate extravasation into the rectal lumen.

rectal than in gastric varices. The resultant patient discomfort may be managed with topical therapies. Our current practice has been revised such that a maximum of $1 \mathrm{ml}$ of cyanoacrylate is injected per session and repeat sessions are performed at weekly intervals if necessary.

\section{Endoscopy_UCTN_Code_TTT_1AS_2AZ}

Competing interests: Yes. Mouen A. Khashab is a consultant for Boston Scientific and Olympus America and has received research support from Cook Medical. relevant disclosures. Payal Saxena, Alba M. Azola, Anthony N. Kalloo, Mouen A. Khashab

Department of Medicine and Division of Gastroenterology and Hepatology, Department of Medicine, The Johns Hopkins Medical Institutions, Baltimore,

\section{References}

1 Seewald S, Sriram PV, Naga M et al. Cyanoacrylate glue in gastric variceal bleeding. Endoscopy 2002; 34: 926-932

2 Helmy A, Al Kahtani K, Al Fadda M. Updates in the pathogenesis, diagnosis and management of ectopic varices. Hepatol Int 2008; 2 : $322-334$

3 Binmoeller KF, Weilert F, Shah JN et al. EUSguided transesophageal treatment of gastric fundal varices with combined coiling and cyanoacrylate glue injection (with videos). Gastrointest Endosc 2011; 74: 1019-1025

Bibliography

Dol http://dx.doi.org/

10.1055/s-0033-1359136

Endoscopy 2014; 46: E28-E29

(c) Georg Thieme Verlag KG

Stuttgart · New York

ISSN 0013-726X

Anthony Kalloo is a founding member, equity holder, and consultant for Apollo Endosurgery. All other authors have no

Corresponding author Mouen A. Khashab, MD Johns Hopkins Hospital 1800 Orleans St, Suite 7125 B

Ahmed A. Messallam, Vivek Kumbhari, Maryland, USA
Baltimore

MD 21205

USA

Fax: +1-443-683-8335

mkhasha1@jhmi.edu 